\title{
Science Indicators to measure papers with the Gross Domestic Product Output (GDP) and Economic Indicators
}

Vinayak. M. Bankapur

Dept. of Library and Information Science, School of Applied Science

Rani Channamma University, Belagavi-Karnataka, India

bankapur@rediffmail.com

Savita N. Nayak

Rani Channamma University, Belagavi \& Librarian, Govt. First Grade College

Ankola, Uttar Kannada, Karnataka, India

savitanageshnayak@gmail.com

\section{S. L. Sangam}

Dept. of Library and Information Science, Dean Faculty of Social Sciences

Karnatak University, Dharwad 580003 India \& Visiting Professor DRTC

Indian Statistical Institute, Bangalore

slsangam@gmail.com

\begin{abstract}
We in this work have worked on the Science and Technology Indicators(S\&T) for scientific output in Indan agriculture as viewed from the citation dataset including the Science Citation Index Expanded (SCIE) database during 1993-2017. Besides we introduce economic indicators and try to correlated with the other science indicators which is based on the scholarly publications of Global and Indian Agricultural Scientists. Further we looked at the correlation coefficient of top fifteen countries in agricultural literature producers with their GDP's, GERD (Gross domestic expenditure in R\&D) and Government expenditure on education. We tried to find the publications for India with an assumption that the publication of present year depends on the GDP of the present year, GERD of the previous year and Educational expenditure (EDP) of last second year by using Least Square linear Regression Analysis. In the analysis we found that both Observed and Predicted values fall on the same linear graph with correlation coefficient 0.9394 \& 0.9613 respectively for Global agricultural publication and $0.929 \& 0.9649$ respectively for Indian agricultural publications.
\end{abstract}

Keywords: Scientometrics, Scientific Productivity, Agricultural Literature, Collaborative Coefficient, S\&T Indicators, Economic Indicators

Received: 9 June 2018, Revised 18 July 2018, Accepted 25 July 2018

DOI: $10.6025 /$ jism/2018/8/4/135-144

C 2018 DLINE. All Rights Reserved 


\section{Introduction}

Indicators are used to measure the scope of the perceived construct, whereas the construct is a measurable entity which can be expressed through measurement of directly observable variables. Science and Technology (S\&T) indicators assist in knowing various dimensions and characteristics of science and technology such as research productivity, collaboration. Economic indicators direct us to know about the health of the country in terms of measurement of scientific activity. S\&T indicators and economic indicators enable a better understanding of the structure, of the impact of policies and programs and of the impact of discipline on society and the economy.

Indicators are constructed from various input and output statistics of the system under study. Input indicators are constructed using the financial statistics. One more input indicator is derived from manpower involved in R\&D of Agricultural Sciences is publication/patent count by a scholar, which is constructed from research papers, patents, standards, significant innovations is manpower indicator. The data of publication count is an output indicator which provides the final output. Counts of patents and papers provide valid indicators of R\&D activity in the subject areas under study and also the institutions from which they originate. Impact Measurement and Linkage Measurement are the two indicators associated with citations and knowledge linkages among subject areas.

\section{Relation between Number of Publications and Economic Indicators}

Growth and development of a nation depends on research and developmental activities for certain extent. Many of the studies reveal that researchers have attempted to relate the research output of a country with economic indicators.

Developing countries where the economy is based on agriculture have become major forces in the global agricultural economy. The agricultural sector is being the core contributor to the Indian Economy contributes 17.35\% to GDP in 2016-17. Indian agriculture stands among the top three nations in terms of production of various agricultural commodities and marks its presence at the global level. Presently the Indian Public Agricultural Research System (IPARS) has been based on central level tier, Indian Council for Agricultural Research (ICAR), which plays a vital role in agricultural education, research, and extension. IPARS also based on a system of state agricultural universities (SAU) which deliver statespecific research and education on Agriculture. Further, the income earned through agricultural research has a direct impact on GDP.

The GDP is defined as the total value of all goods and services produced within a country during a specified period. GDP is generally computed as:

$$
\text { GDP }=\text { Consumption }+ \text { Investment }+ \text { Govt. Expenditure }+ \text { Exports }- \text { Imports }
$$

\section{Literature Review}

Several researchers have compared the economic indicators, such as the GDP and/or per capita income with the non-economic indicators such as the number of publications. An attempt is made to correlate the research impact with GDP, agricultural value added on GDP and R\&D investment trends with top ten research output providing countries. Kishida and Matsui (1997) examined the machine-readable files of IBSS 1981-1985 in social sciences field. They examined the correlation between the number of published monographs, population, number of people attaining a university education and GDP. A regression model was incorporated to test the variation of the number of monographs by countries and R2 value equal to 0.77 was found. Therefore there exists a low correlation between these two variables. Hart and Somerfield (1998) studied the relationship between GDP and publications counts of chemical engineering field were obtained from earlier studies. The study confined to five English speaking countries over a period of 26 years, they concluded that GDP is linearly correlated with the chemical engineering literature. They computed the correlation coefficient between a number of publications $(x)$ and GDP $(y)$ (dependent variable) for each country. Authors have opined that GDP and the number of publications are linearly related $(y=a+b x)$ i.e. $y$ can be estimated from $x$. But, in a practical sense, there are several aspects influence the GDP, it may be inappropriate to estimate

$\mathrm{y}$ based on $\mathrm{x}$. Possibly an attempt can be made to estimate the value of $\mathrm{x}$ using $\mathrm{y}$ as the independent variable. Inonu (2003) opted the clustering of countries share a common cultural attitude towards scientific research. A classification of countries with respective ranks in the scale of publications per million people and GDP per capita (PPP) was correlated and found that there was no correlation. Meo, S. A.et. al(2013) studied Impact of GDP per capita, Spending on R\&D, Number of Universities and indexed Scientific Journals on Research Publications in various science and social science subjects among 40 Asian countries during the

136 Journal of Information \& Systems Management Volume 8 Number 4 December 2018


period 1996- 2011which where retrieved through World Bank, Scopus, and Web of Science. They concluded that there was no association between the per capita GDP and research outcome. Ye's study (2007) study reveals the strongest relationship between country development level and scientific indicators. The correlation was determined for 24 countries by using IMF, WIPO and UNESCO data between GDP and scientific production for a single year (2001) A report (IDEA Consult, 2008) correlates the levels of R\&D spending with economic growth levels. Findings reveal that R\&D intensities were temporarily influenced by the levels of GDP growth. However, GDP depends on governance structure, policy matters, and industrial structures and academic priorities; therefore 'one dress fits all' approach does not fit for all the countries. Vinkler (2007) related GDP and number of publications in the field of longitudinal studies resulted in meaningful correlation for countries. However, he found that there is no direct relationship between GDP and information production. It was observed that R\&D expenditures do not depend on actual need; it should be noted there are other influential factors; for instance, developed rich countries can always afford to spend more money on scientific research than poor countries. Nguyen \& Pham (2011), found that there exists a strong relationship between scientific output between scientific output and knowledge economy index of ten South East Asian countries. Akhmat, Zaman, Shukui, Javed \& Khan (2014) studied empirical relationship between educational indicators and research productivity (publications, citations, and patents) for the top twenty countries worldwide and found that the educational indicators were important to increase research productivity. Many previous studies reveal that there exists a meaningful correlation between economic indicators and research output. However, it should not be ignored that these kinds of assessments can change from country to country and period to period.

\section{Objectives of the Study}

Main objectives of the present study were to analyze the data under the following headings:

- To ascertain the correlation coefficients of publication with economic Indicator GDP/GERD/ EDP for top fifteen agricultural literature producing countries

- To predict the publication count (dependent variable) depending on the empirical formula derived using GDP, GERD and EDP.

\section{Hypothesis:}

1. Ho: There exists high level correlation between India Agriculture Publication and Economic Indicator;

H1: There is no correlation between India Agriculture Publication and Economic Indicator;

2. Ho: There is no difference between the observed value of the publications and predicted value of the publications obtained from the assumed equations.

H1: There is difference between the observed value of the publications and predicted value of the publications obtained from the assumed equations

\section{Methodology}

The indicator related to publications is known as a bibliometric indicator and is obtained from Web of Science (WOS) - Science Citation Index Expanded database. A total of 646279 articles global agricultural literature with 547403 articles for top fifteen countries producing agricultural literature including 41146 articles for Indian agricultural literature for the period 1993 to 2017 has been extracted using the advanced search feature of the web of science database. The retrieved records were examined, classified, and analyzed correlating to the objectives in view.

The input S\&T indicator indicators used in our study are GDP (Constant 2010, US\$), which is collected from the World Bank database (IBRD, IDA). GERD is the total expenditure in R\&D of a country with respect to the overall expenditure. Further, the data is analyzed using MS Excel spreadsheet.

\section{Results and Discussion}

\subsection{Year wise Correlation Coefficients of Publication with Economic Indicator GDP}

An attempt has been made to study the relationship between the GDP growth rate and numbers of publications. The yearly and country wise correlation coefficients were computed. The results are given under Table 1 


\begin{tabular}{|c|c|c|c|}
\hline \multirow[t]{2}{*}{ Country } & \multirow[t]{2}{*}{ Total Publications (top 15 countries) } & \multirow[t]{2}{*}{ Publication Contribution (\%) } & Correlation Coefficients (r) \\
\hline & & & $P u b / G D P$ \\
\hline 1993 & 13039 & 2.38 & 0.80 \\
\hline 1994 & 13524 & 2.47 & 0.79 \\
\hline 1995 & 13656 & 2.49 & 0.79 \\
\hline 1996 & 13470 & 2.46 & 0.84 \\
\hline 1997 & 14586 & 2.66 & 0.88 \\
\hline 1998 & 14586 & 2.66 & 0.91 \\
\hline 1999 & 14418 & 2.63 & 0.90 \\
\hline 2000 & 15119 & 2.76 & 0.89 \\
\hline 2001 & 14398 & 2.63 & 0.92 \\
\hline 2002 & 15151 & 2.77 & 0.94 \\
\hline 2003 & 16461 & 3.01 & 0.92 \\
\hline 2004 & 23460 & 4.29 & 0.93 \\
\hline 2005 & 21543 & 3.94 & 0.94 \\
\hline 2006 & 22544 & 4.12 & 0.94 \\
\hline 2007 & 29511 & 5.39 & 0.93 \\
\hline 2008 & 26391 & 4.82 & 0.87 \\
\hline 2009 & 26096 & 4.77 & 0.87 \\
\hline 2010 & 29314 & 5.36 & 0.89 \\
\hline 2011 & 27298 & 4.99 & 0.84 \\
\hline 2012 & 28118 & 5.14 & 0.84 \\
\hline 2013 & 29192 & 5.33 & 0.86 \\
\hline 2014 & 29068 & 5.31 & 0.86 \\
\hline 2015 & 29981 & 5.48 & 0.84 \\
\hline 2016 & 32514 & 5.94 & 0.86 \\
\hline 2017 & 33965 & 6.20 & 0.89 \\
\hline Total & 547403 & Significa & at $p<0.05$ \\
\hline
\end{tabular}

Table 1. Year-wise Correlation Coefficients of Publication with Economic Indicators

It is clear from Table 1 that the correlation coefficient (r) varies from 0.79 to 0.94 (high coefficient value) over a period of time and decreasing trend is seen for the total publication of fifteen countries to Publication count.; The correlation ranges between high to very high correlation, and the positive percentage indicates there is a linear relationship between the numbers of publications and other economic factors under consideration. Higher the GDP, the higher the number of publications to some extent can be predicted using the values of the table.

\subsection{Country wise Correlation Coefficients of Publication with Economic Indicators}

Correlation coefficients ( $r$ ) were computed for top ten publication countries to study whether there exists a relationship between the number of publications and the GDP /EDP/GERD over a period of time. Table 2 presents the country wise correlation coefficients of publication with economic indicators for the period 1993 to 2017(25 years).

\section{Journal of Information \& Systems Management Volume 8 Number 4 December 2018}




\begin{tabular}{|c|c|c|c|c|c|}
\hline \multirow[t]{2}{*}{ Country } & \multirow[t]{2}{*}{ Total Publications } & \multirow[t]{2}{*}{ Publication Contribution(\%) } & \multicolumn{3}{|c|}{ Correlation Coefficients (r) } \\
\hline & & & $P u b / G D P$ & $P u b / E D P$ & PUb/GERD \\
\hline USA & 160,357 & 25 & 0.39 & 0.32 & 0.34 \\
\hline CHINA & 48,485 & 8 & 0.99 & 0.99 & 0.99 \\
\hline BRAZIL & 48,136 & 7 & 0.93 & 0.94 & 0.94 \\
\hline INDIA & 41,146 & 6 & 0.95 & 0.92 & 0.91 \\
\hline CANADA & 31,390 & 5 & 0.71 & 0.71 & 0.75 \\
\hline GERMANY & 31,205 & 5 & 0.93 & 0.96 & 0.97 \\
\hline AUSTRALIA & 28,230 & 4 & 0.88 & 0.89 & 0.87 \\
\hline JAPAN & 27,250 & 4 & 0.34 & 0.59 & 0.70 \\
\hline SPAIN & 28,447 & 4 & 0.95 & 0.89 & 0.96 \\
\hline FRANCE & 24,820 & 4 & 0.88 & 0.85 & 0.89 \\
\hline $\begin{array}{l}\text { UNITED } \\
\text { KINGDOM }\end{array}$ & 21,049 & 3 & -0.37 & -0.39 & -0.39 \\
\hline ITALY & 21,463 & 3 & 0.86 & 0.75 & 0.93 \\
\hline NETHERLA NDS & 14,225 & 2 & 0.82 & 0.82 & 0.89 \\
\hline KOREA & 11,621 & 2 & 0.97 & $*$ & 0.97 \\
\hline MEXICO & 9,579 & 1 & 0.89 & 0.89 & 0.89 \\
\hline Global output & 646279 & 100 & 0.97 & 0.96 & 0.98 \\
\hline
\end{tabular}

Table 2. Country-wise Correlation Coefficients of Publication with Economic Indicators

It may be observed from the table 2 that most of the countries have $r>90$ under GDP V/s publications, the correlation coefficient is very high for China, Korea, India, Spain, Brazil, Germany, Mexico, Australia, France, Italy, Netherlands, whereas Canada exhibits high correlation and a moderate level relation is observed for USA and Japan, and the United Kingdom shows no correlation. Similarly when correlation for Government expenditure on education to GDP and Publications is studies show that high correlation exists for China, India, Spain, Brazil, Germany, Mexico, Australia, France, Netherlands, Italy, whereas the UK shows no correlation between both entities. The relation between GERD to publication shows similar results as that of GDP and EDP. The negative low-level correlation for India and positive high correlation for US, China, Brazil and Canada. When the growth percentage of both GDP and publications is tested it shows a high level of correlation between most of the countries under study. Similarly, the Global agricultural output shows a very high correlation with all the economic indicators under consideration.

\subsubsection{Correlation Coefficient of Indian Agricultural Literature Data V/S Economic Indicators}

An attempt has been made to estimate the number of publications based on parameters like GDP (Gross Domestic Production), GERD (Gross domestic expenditure in R\&D) of the previous year and Government expenditure on education (EDP) of previous two years for India over a period 1998-2017(20 years). An assumption is made that the publication of the present year depends on the GDP of the present year, GERD of the previous year and Educational expenditure (EDP) of last second year. Table 3 gives data on publication count, economic indicators, and their relationship both. The positive correlation values show there is a linear relationship between the variables. 
The following equation has been used to fit the empirical data:

$$
P U B=\alpha 1 * G D P(t)+\alpha 2 * G E R D(t-1)+\alpha 3 * E D P(t-2)
$$

Where $P U B \rightarrow$ Number of Publications; $G D P(t) \rightarrow G D P$ data for the current year (say $t$ );

$\operatorname{GERD}(t-1) \rightarrow$ Research and Development expenditure for $t-1$ year;

$E D P(t-2) \rightarrow$ Education expenditure of $(t-2)$ years; $\alpha 1, \alpha 2, \alpha 3$ are constants

Table 3 gives data on GDP, last year's GERD and previous 2nd year Government expenditure on education (EDP) for Indian scholarly publications in the field of agricultural science and it forms the preliminary data for the further study.

\begin{tabular}{|l|l|l|l|l|l|}
\hline Year & Pub & GDP & GERD (t-1) & EDP(t-2) & Total \\
\hline $\mathbf{1 9 9 8}$ & 1165 & 415730874171 & 2773272847 & 51644427614 & 470148574632 \\
\hline $\mathbf{1 9 9 9}$ & 1225 & 452699998387 & 2880807093 & 54663815557 & 510244621036 \\
\hline $\mathbf{2 0 0 0}$ & 1305 & 462146799338 & 3226619239 & 58864458139 & 524237876715 \\
\hline $\mathbf{2 0 0 1}$ & 1217 & 478965491061 & 3434028007 & 76777147105 & 559176666173 \\
\hline $\mathbf{2 0 0 2}$ & 1105 & 508068952066 & 3457939259 & 77319519767 & 588846411092 \\
\hline $\mathbf{2 0 0 3}$ & 1276 & 599592902016 & 3618111428 & 80133372787 & 683344386232 \\
\hline $\mathbf{2 0 0 4}$ & 1184 & 699688852930 & 4240740718 & 85002530448 & 788932124096 \\
\hline $\mathbf{2 0 0 5}$ & 1137 & 808901077223 & 5208203946 & 74414275765 & 888523556933 \\
\hline $\mathbf{2 0 0 6}$ & 1196 & 920316529730 & 6561643758 & 78343183491 & 1005221356979 \\
\hline $\mathbf{2 0 0 7}$ & 1713 & 1201111768410 & 7345046224 & 90665352500 & 1299122167134 \\
\hline $\mathbf{2 0 0 8}$ & 2171 & 1186952757636 & 9787019023 & 107619149079 & 1304358925738 \\
\hline $\mathbf{2 0 0 9}$ & 1984 & 1323940295874 & 10294203876 & 140454530903 & 1474689030654 \\
\hline $\mathbf{2 0 1 0}$ & 2132 & 1656617073125 & 11182132133 & 138798817198 & 1806598022456 \\
\hline $\mathbf{2 0 1 1}$ & 2027 & 1823049927772 & 13615735724 & 148164809786 & 1984830473282 \\
\hline $\mathbf{2 0 1 2}$ & 2190 & 1827637859136 & 15147721850 & 196038765792 & 2038824346778 \\
\hline $\mathbf{2 0 1 3}$ & 2213 & 1856722121394 & 15185842972 & 247295080772 & 2119203045138 \\
\hline $\mathbf{2 0 1 4}$ & 2119 & 2039127446299 & 15427504107 & 255725278562 & 2310280228968 \\
\hline $\mathbf{2 0 1 5}$ & 2517 & 2102390808997 & 16943109951 & 260872808236 & 2380206727184 \\
\hline $\mathbf{2 0 1 6}$ & 2740 & 2274229710530 & 13190399936 & 286501085508 & 2573921195974 \\
\hline $\mathbf{2 0 1 7}$ & 2648 & 2597491162898 & 14268517204 & 295389702117 & 2907149382218 \\
\hline $\mathbf{C o r r e l a t i o n ~ C o e f i c i e n t ( r )}$ & $\mathbf{0 . 9 5}$ & $\mathbf{0 . 9 2}$ & $\mathbf{0 . 9 0}$ & $\mathbf{0 . 9 5}$ \\
\hline
\end{tabular}

Table 3. Correlation Coefficient of Indian Agricultural Scholarly Publications Data V/S Economic Indicators under study

Table 4 provides an overview of the correlation coefficient(R), the coefficient of determination (R2), significance level. In the equation Publication (Pub) is the dependent variable. The values are predicted using the least square method of regression analysis at significance level $0.05(5 \%)$. 


\begin{tabular}{|c|c|c|c|c|c|c|}
\hline $\begin{array}{l}\text { Dependent } \\
\text { Variable: }\end{array}$ & \multicolumn{6}{|l|}{$P U B$} \\
\hline Method: & \multicolumn{6}{|c|}{ Least Square linear Regression Analysis } \\
\hline Sample : 1998-2017 & \multicolumn{4}{|c|}{ Level of Significance considered $\alpha=0.05$} & Significance F & $2.85 \mathrm{E}-10$ \\
\hline Observations : & 20 & \multicolumn{5}{|c|}{ Degree of freedom df: 19} \\
\hline Variable & $\mathrm{R}$ & $\mathrm{R}^{2}$ & Adj $R^{2}$ & \multicolumn{2}{|l|}{ SE } & $P$ value \\
\hline GDP (t) & 0.95 & 0.89 & 0.89 & \multicolumn{2}{|c|}{$6.12 \mathrm{E}-11$} & 0.000000003 \\
\hline $\operatorname{GERD}(t-1)$ & 0.92 & 0.84 & 0.83 & \multicolumn{2}{|c|}{$1.05 \mathrm{E}-08$} & 0.000000014 \\
\hline EDP(t- 2) & 0.90 & 0.82 & 0.81 & \multicolumn{2}{|c|}{$6.75 \mathrm{E}-10$} & 0.00000000067 \\
\hline Total & 0.95 & 0.90 & 0.89 & \multicolumn{2}{|c|}{$5.44 \mathrm{E}-11$} & 0.000000000054 \\
\hline \multicolumn{7}{|c|}{$\begin{array}{l}\mathrm{R} \rightarrow \text { Correlation Coefficient; } \mathrm{R}^{2} \rightarrow \text { Coefficient of Determination Adj } \mathrm{R}^{2 \rightarrow} \text { Adjusted } \mathrm{R}^{2} \text { (more than } 1 \\
\text { variable) } \mathrm{SE} \rightarrow \text { Standard Error (Regression );Total } \rightarrow \mathrm{GDP}(\mathrm{t})+\mathrm{GERD}(\mathrm{t}-1)+\mathrm{EDP}(\mathrm{t}-2)\end{array}$} \\
\hline
\end{tabular}

Table 4. Estimation of the Publications based on GDP, GERD, EDP and Total Square Regression Analysis Values Considered to Predict the Significance

The table 4 shows that all the parameters are significant at $0.05 \%$. ' $R$ ' value is above $90 \%$ for GDP of the present year, GERD of last year and the EDP of last two year. Overall $\mathrm{R}$-value is $95 \%$ whereas $R^{2}$ is 0.90 and the adjusted $R^{2}$ is 0.89 .The significance value $=0.00000000028$ is very much lesser than 0.05 . Thus the prediction of publications can be attempted as the data is highly significant for the above regression equation.

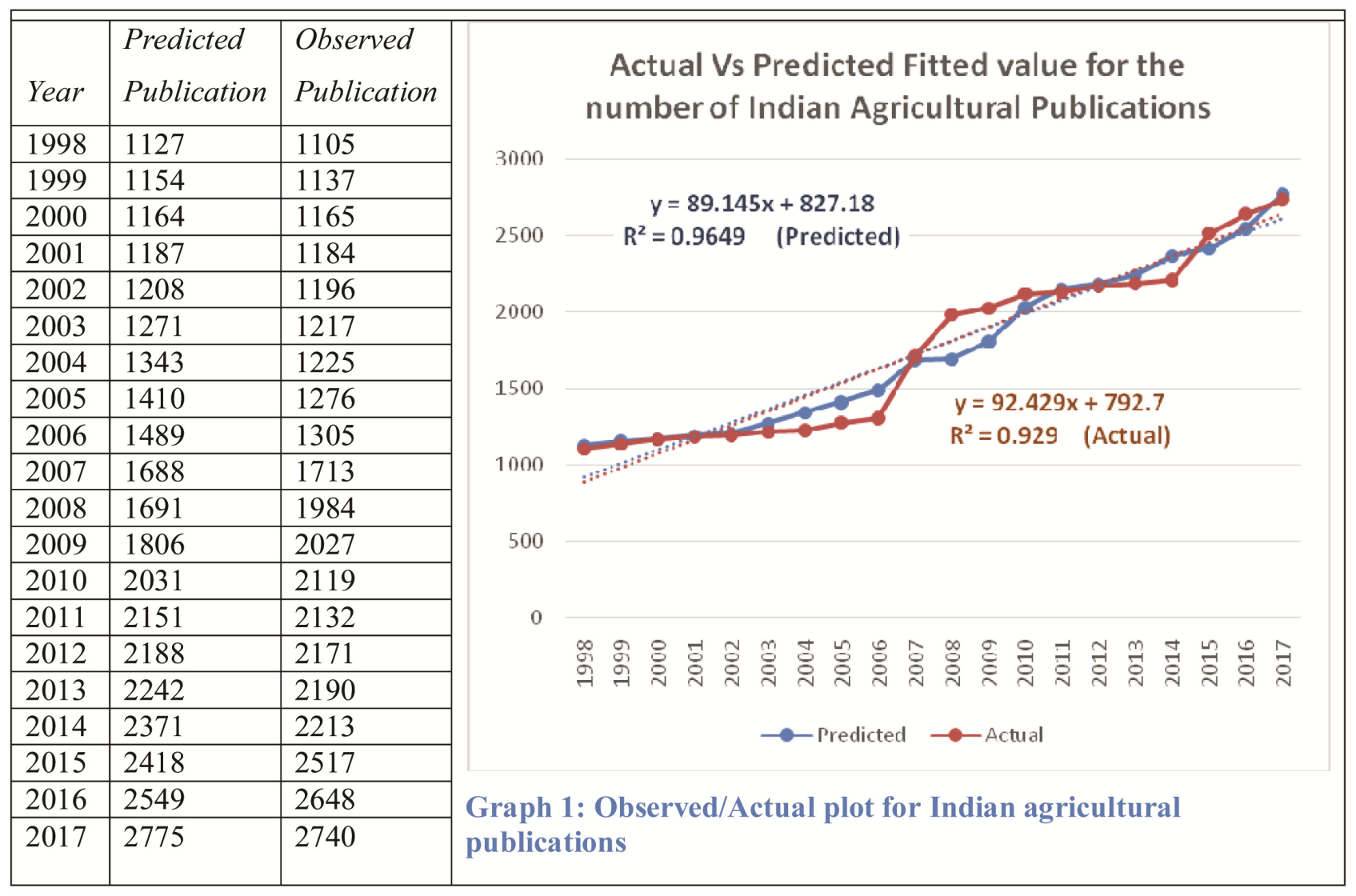

Table 5. Actual Vs Predicted Fitted value for the number of Indian Agricultural Publications 
The table 5 interprets the values of Observed Publications V/S Predicted Publications in case of Indian Agricultural publication. The Graph 1 denotes Observed and Predicted values fall on the same linear graph.

The observed values for publications fit in the linear equation

$$
y=92.429 x+792.7 \text { with } R^{2}=0.929
$$

Whereas the predicted values for publication fall on linear equation

$$
y=89.145 x+827.18 \text { where } R^{2}=0.9649
$$

A similar study has been undertaken for global research agricultural output and is explained below.

\section{Correlation Coefficient of Global Agricultural Literature Data V/S Economic Indicators}

Table 6 gives data on GDP, last year's GERD and previous 2nd year Government expenditure on education for global agricultural

\begin{tabular}{|c|c|c|c|c|c|}
\hline Year & $P u b$ & GDP & $\operatorname{GERD}(t-1)$ & $E D P(t-2)$ & Total \\
\hline 1998 & 18193 & 31346914162278 & 621591140322 & 4574651726394 & 36543157028994 \\
\hline 1999 & 17807 & 32512421581403 & 618928366738 & 4559159255470 & 37690509203611 \\
\hline 2000 & 18191 & 33571705209640 & 621737900749 & 4546962309880 & 38740405420269 \\
\hline 2001 & 17551 & 33367434839454 & 669509462935 & 4716022596938 & 38752966899327 \\
\hline 2002 & 18004 & 34644767861719 & 690351065028 & 4485233488423 & 39820352415170 \\
\hline 2003 & 19150 & 38882914196342 & 694335829700 & 4734451912249 & 44311701938291 \\
\hline 2004 & 26537 & 43787738174825 & 707131905592 & 5032225417769 & 49527095498186 \\
\hline 2005 & 25760 & 47411807968475 & 790335151071 & 5744038772147 & 53946181891693 \\
\hline 2006 & 25579 & 51340956869474 & 868010548069 & 6014156114406 & 58223123531949 \\
\hline 2007 & 33184 & 57833267163667 & 934985817792 & 6532166436744 & 65300419418203 \\
\hline 2008 & 31314 & 63433456720740 & 1016525762691 & 7177088523682 & 71627071007113 \\
\hline 2009 & 30518 & 60138443581995 & 1130820162574 & 8071777663485 & 69341041408054 \\
\hline 2010 & 33842 & 65956672976971 & 1274563156750 & 9106012165010 & 76337248298731 \\
\hline 2011 & 32238 & 73297338575870 & 1232636797696 & 8522227731934 & 83052203105500 \\
\hline 2012 & 32798 & 74965622671175 & 1342716298515 & 9450007964452 & 85758346934142 \\
\hline 2013 & 33514 & 77050588613142 & 1482701211412 & 10002898859504 & 88536188684058 \\
\hline 2014 & 32802 & 79131444226985 & 1566617831537 & 10680738486026 & 91378800544548 \\
\hline 2015 & 35712 & 74842734112388 & 1589328171147 & 10877851854930 & 87309914138466 \\
\hline 2016 & 38117 & 75936811478760 & 1703788969307 & 11056538290619 & 88697138738687 \\
\hline 2017 & 39829 & 80683787437858 & 1667066534070 & 10457303838846 & 92808157810773 \\
\hline \multicolumn{2}{|c|}{$\begin{array}{l}\text { Correlation Coefficient } \\
\text { (r) }\end{array}$} & 0.95 & 0.91 & 0.92 & 0.95 \\
\hline
\end{tabular}
literature and it forms the preliminary data for the further study.

Table 6. Correlation Coefficient of Global Agricultural Scholarly Publications Data V/S economic Indicators under Study 142 Journal of Information \& Systems Management Volume 8 Number 4 December 2018 
Table 7 provides an overview of the correlation coefficient(R), the coefficient of determination (R2), significance level. In the equation Publication (Pub) is the dependent variable. The values are predicted using the least square method of regression analysis at significance level $0.05(5 \%)$.

\begin{tabular}{|c|c|c|c|c|c|c|c|}
\hline Dependent Variable: & \multicolumn{7}{|l|}{$P U B$} \\
\hline Method: & \multicolumn{7}{|c|}{ Least Square linear Regression Analysis } \\
\hline Sample:1998-2017 & \multicolumn{4}{|c|}{ Level of Significance considered $\alpha=0.05$} & \multicolumn{2}{|c|}{ Significance F } & 0.0000000001051 \\
\hline Observations : & 20 & \multicolumn{6}{|c|}{ Degree of freedom df: $\quad 19$} \\
\hline Variable & $\mathrm{R}$ & $\mathrm{R}^{2}$ & Adj $\mathrm{R}^{2}$ & \multicolumn{2}{|c|}{ SE } & \multicolumn{2}{|c|}{$\mathrm{P}$ value } \\
\hline GDP (t) & 0.95 & 0.91 & 0.90 & \multicolumn{2}{|c|}{0.00000000002926} & \multicolumn{2}{|c|}{0.000000003} \\
\hline $\operatorname{GERD}(\mathrm{t}-1)$ & 0.91 & 0.83 & 0.82 & \multicolumn{2}{|c|}{0.00000000185133} & \multicolumn{2}{|c|}{0.000000014} \\
\hline EDP(t- 2) & 0.92 & 0.84 & 0.83 & \multicolumn{2}{|c|}{0.00000000028400} & \multicolumn{2}{|c|}{0.00000000067} \\
\hline Total & 0.95 & 0.91 & 0.90 & \multicolumn{2}{|c|}{0.00000000002567} & \multicolumn{2}{|c|}{0.000000000054} \\
\hline
\end{tabular}

Table 7. Estimation of the Publications based on GDP, GERD,EDP and Total Square Regression Analysis Values Considered to Predict the Significance for Global Agricultural Literature

The table 7 shows that all the parameters are significant at $0.05 \%$. $R$-value is above $90 \%$ for GDP of the present year, GERD of last year and the EDP of last two year. Overall R-value is $95 \%$ whereas $R^{2}$ is 0.91 and the adjusted $R^{2}$ is 0.90 for the formulated formula with respect to Global agricultural literature. The significance value $\mathrm{F}=0.00000000010$ is very much lesser than 0.05 . Thus the prediction of publications can be attempted as the data is highly significant for the above regression equation.

The table 8 interprets the values of Observed Publications V/S Predicted Publications in case of global Agricultural publication. The Graph 2 denotes Observed and Predicted values fall on the same linear graph. The observed values for publications fit in the linear equation.

$$
y=1230.2 x+15115 \text { with } R^{2}=0.9394
$$

Whereas the predicted values for publication fall on linear equation

$$
\mathrm{y}=1184.9 x+15591 \text { with } R^{2}=0.9613
$$

It can be interpreted from the data that the research output depends on GDP of the present year, GERD of the previous year and EDP of last second year in both the cases. It is obvious that the as GDP value increase the publication count also increases, thereby relating both the Publication count and Economic Indicators.

\section{Conclusion}

The relation between the GDP and number of publications show that there exists a linear relationship between these indicators. For most of the countries, a positive high correlation is seen. The correlation is significant between the economic indicators indicating that the higher the GDP higher the number of publications. The correlation coefficient among other indicators like GERD, EDP shows that the increase in budget in the Research and Development results in an increase in the number of publications.

\section{References}

[1] Hart, P. W., Somerfield, J. T. (1998). The relationship between growth in the gross domestic product (GDP) and growth in the chemical engineering literature in five different countries. Scientometrics 42 (3) 299-311. 


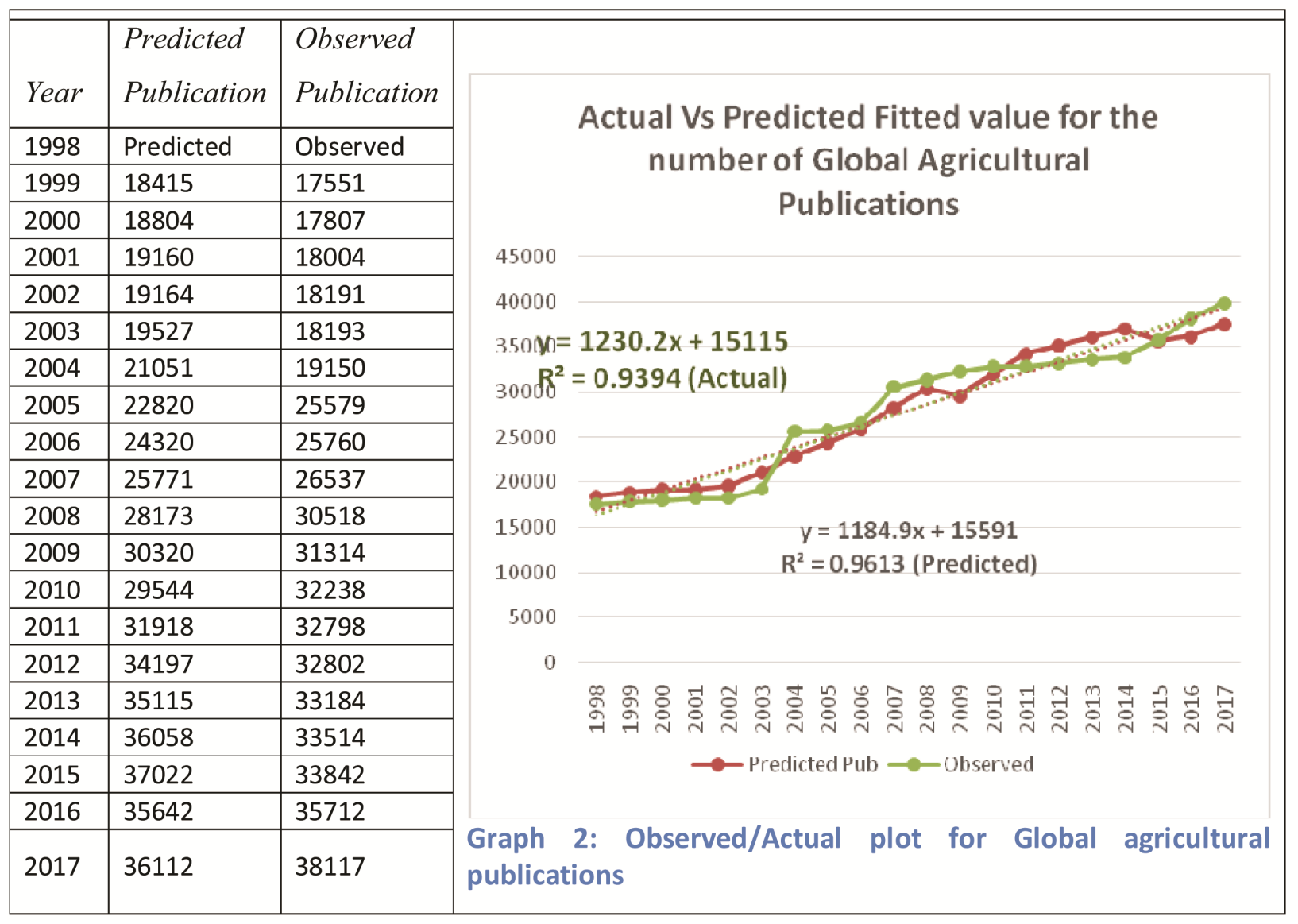

Table 8. Actual Vs Predicted Fitted value for the number of Global Agricultural Publications

[2] Inonu, Erdal. (2003). The influence of cultural factors on scientific production. Scientometrics, 56 (1)137-146.

[3] Meo, S. A., Al Masri, A. A., Usmani, A. M., Memon, A. N., Zaidi, S. Z. (2013). Impact of GDP, spending on R\&D, number of universities and scientific journals on research publications among Asian countries. PLoS One, 8 (6) e66449.

[4] Singh, V. (1999). Indian agriculture. Indian Econ. Data Res. Centre, New Delhi, 397-478.

[5] Kishida, Kazuaki., Matsui, Sachiko. (1997). International publication pattern in Social sciences: a quantitative analysis of the IBSS files. Scientometrics, 40 (2) 277-298.

[6] Elango, B., Rajendran, P. (2015). Global Tribology Research Output (1998 - 2012): A Macro-Level Scientometric Study. Journal of Information Science Theory and Practice, 3 (4) 35-48.

[7] Akhmat, G., Zaman, K., Shukui, T., Javed, Y., Khan, M. M. (2014). The relationship between educational indicators and research outcomes in a panel of top twenty nations: Windows of opportunity. Journal of Informetrics, 8 (2) 349-361.

[8] IDEA Consult. (2008). A time series analysis of the development of national R\&D intensities and national public expenditures on R\&D. Final Study Report for Specific Assignment 4 (SPA4): Literature Review, Feasibility Study, Collection of Field Statistics, Calculation of Indicators, Survey, Conclusions. Brussels. Retrieved February 1, 2017, from http://ec.europa.eu/invest-inresearch/ pdf/download_en/spa4_final_report_final.pdf

[9] Nguyen, T.V., Pham, L.T. (2011). Scientific output and its relationship to knowledge economy: An analysis of ASEAN countries. Scientometrics, 89 (1) 107-117.

[10] Vinkler, P. (2007). Correlation between the structure of scientific research, scientometric indicators and GDP in EU and nonEU countries. Scientometrics, 74 (2) 237-254.

[11] Ye, F. Y. (2007). A quantitative relationship between per capita GDP and scientometric criteria. Scientometrics, 71 (3) 407-413.

144 Journal of Information \& Systems Management Volume 8 Number 4 December 2018 